\title{
In Pursuit of Coherent and Formalizable Understanding: Reflections on David Tall's Three Worlds Framework
}

\author{
How Humans Learn to Think Mathematically: Exploring \\ the Three Worlds of Mathematics. Tall, D. (2013). New York, \\ NY, USA: Cambridge University Press
}

\author{
Paul Christian Dawkins ${ }^{1}$
}

Published online: 15 May 2015

(C) Springer International Publishing Switzerland 2015

In "How Humans Learn to Think Mathematically," David Tall endeavors to account for mathematical thinking and learning from childhood to mathematical research; he does this while maintaining an eye toward formalization, as one might expect of the editor of “Advanced Mathematical Thinking” (Tall 1991) - a seminal work in proof-oriented undergraduate mathematics education. Indeed, "How Humans..." directly reflects Tall's career in many ways, lending it an autobiographical flavor. I appreciated the fascinating insight into Professor Tall's own thinking and learning about mathematical thinking and learning. The book serves as a synthesis of many of the major projects and ideas from Tall's career and makes frequent reference to his work with various graduate students. As a result, many of the elements that comprise his overarching "three worlds" framework will be familiar to many mathematics educators.

Like most mathematics education frameworks, the three worlds framework partitions mathematical thinking and doing in various ways, but most prominently into the embodied, symbolic, and formal worlds of mathematics. Tall provides a number of examples to show how students can encounter the same "concept" over the course of their schooling through the three worlds, generally in the embodied and symbolic worlds before formalizing. Unlike the authors of some frameworks, Tall tries to avoid privileging any one of these three ways of thinking about mathematics, because his ultimate goal is the coordination of various meanings into a unified whole called a crystalline concept. Unlike many texts, Tall's presentation will be accessible to anyone with advanced mathematics training, although it reflects the sensibilities of someone who has engaged in pedagogical conversations with mathematicians, as evidenced by Byers' (2014) complimentary review. Though Tall casts a vision for flexible and

Paul Christian Dawkins

dawkins@math.niu.edu

1 Department of Mathematical Sciences, Northern Illinois University, DeKalb, IL 60115, USA 
coherent understanding across the worlds, he acknowledges several barriers to understanding the unity of crystalline concepts. It was primarily these barriers that fostered the questions I was left pondering at the close of the book.

\section{The "Worlds" Metaphor}

Before I discuss those barriers and my questions, I encourage the reader to reflect on Tall's central metaphor: worlds. Tall cites Lakoff and Núñez (2000) exploration of mathematical metaphors as central to his own thinking about how people learn to think mathematically, but he does not explain why he chose the metaphor at the heart of his framework. Does Tall intend the three worlds to be student or cultural constructions in the sense of Goodman's (1978) worldmaking or Holland et al. (1998) figured worlds? There is little evidence of this as Tall assumes the coherence of mathematical concepts, treating mathematics as existing somewhat independently of particular knowers. While he clearly revels in exploring the interface between mathematical concepts and the "thinkable concepts" with which people reason, Tall's descriptions at times sound almost Platonic. Are these worlds truly independent and inherent to mathematics, so that Tall is carving mathematical thinking at its joints? Tall clearly acknowledges that there is plenty of overlap between the worlds and that the formal world can legitimize certain embodiments or symbolisms. Why then these three? The choice and definition of the three worlds is justified by Tall's rich history of research and the repeated appearance of key distinctions within mathematics education theorizing (e.g., process vs. object, observation vs. deduction). The three worlds are ultimately useful researcher constructs. They are not fully distinct, but Tall claims they are comprehensive. However, I was unclear how the metaphor supported Tall's grand intention that students should flexibly coordinate meanings of all three types.

\section{Barriers to Unifying the Worlds}

As the title suggests, Tall focuses on successful learning. However, for the mathematics education community I think it is always important to keep an eye on the challenges students face along such a path, generating the question: what are the barriers to developing the crystalline concepts that unify the three worlds? Tall makes the observation that in many ways founded the modern study of mathematics education: many difficulties in student learning are direct results of prior learning. Tall calls these helpful or problematic "met-befores" (a pun on "metaphors"), but the principle is common in mathematics educators' discussion and practice. In line with Tall's focus on the formal world, I shall focus on the barriers there encountered.

Tall acknowledges the discontinuity between formal mathematics and the other two worlds. He rightly generalizes van Hiele's progression from recognition and description (empirical) to definition and deduction (formal). Students begin in the embodied and symbolic worlds before formalizing. However, formalizing in many ways "involves a total reversal of meaning" (p. 149) because numbers are no longer specific objects of study, but merely an example of a set that exhibits key properties (a group, a ring, a field, etc.). Tall celebrates Hilbert's famous observation that proofs depending only 
upon axioms (properties), rather than the objects to which they refer, apply to any mathematical objects that exhibit the relevant properties. As such, formal mathematics is taken to be certain and "future-proofed" (p. 152). The problem is that this suggests that one must approach formal mathematics based solely upon formal meanings rather than using the embodied and symbolic "thinkable concepts" that students have met before. While some teachers of axiomatics truly propose that students ignore what they already know (e.g., Kershner and Wilcox 1950), Tall clearly rejects this, instead proposing that certain proofs can legitimize the appropriate use of particular embodiments and symbolisms (such as the local straightness approach to calculus). However, I think the issue remains regarding how and when a student truly shifts from the quasi-empirical or procedural reasoning of the prior worlds to the deductive reasoning of the formal world. Specifically, from the perspective of student reasoning, what changes and how does it happen?

\section{Transition to the Formal World}

I appreciate Tall's emphasis on well-chosen embodiments and symbolisms that are formalizable. Some of the most exciting research in undergraduate mathematics education reports on efforts to find thinkable concepts that students can access and formalize (e.g., Larsen 2009; Oehrtman 2009), and thus to create greater continuity between students' embodied and symbolic thinkable concepts and the formal mathematical expression of those concepts. However, this glosses over two important matters: what stays the same across the three worlds and what indicates that a concept has become formal? Considering learning and its observation, one might ask the specific questions below.

First, do students perceive similarity between embodied, symbolic, and formal expressions of what experts consider the "same" concept? The book provides several examples of the same idea accessed in all three worlds, assuming that they all express the same "concept." Much as Thompson (1994) complained about the "representations" literature, are we assuming there is some underlying unity where students may possess only some constellation of loosely tied meanings?

Second, how can one empirically claim that a student has transitioned into the formal world in their understanding of a concept? While I think we have many accounts of students acting formally, we have fewer accounts that document the learning/ transition process. I posit that what is fundamentally at stake in the formal world is a set of epistemic commitments shared among most mathematicians: commitment to verifying claims in an a priori manner. How and when do students transition into this new epistemic world? Do they need to perceive the epistemic game being played? Do they need only to abide by the rules imposed by their professors (i.e., produce valid proofs)? We can imagine a range of epistemic views a student might hold regarding a particular theorem/proof:

- that the theorem is true,

- that the theorem must be true (as in Simon et al.'s 2010, notion of anticipations),

- that the conclusions of the theorem are logical entailments of the hypotheses,

- that this is a valid proof of this theorem, or

- that this theorem must be true for any mathematical system that satisfies these axioms. 
Which of these views of truth (which are generally implicit for students) mark formal rather than embodied or symbolic thinking? Could different students engage with or even produce the same proof text while reasoning in different worlds? What is more, how do we truly motivate the need for the epistemological and methodological strictures that Tall celebrates as indicative of the formal world of mathematics? Metaphorically, we might want to distinguish between students who visit the formal world as tourists, simply trying not to break any taboos, from students who "go native," adopting the practices, values, and language of the formal world. What does such a transition look like?

\section{What Might Have Been Missed?}

Reflecting on these questions revealed what I felt was an important gap in the impressively ambitious and far-reaching framework that Tall compiles in the book: students' conscious reflection on their own mathematics. Tall cites cognitive science texts that discuss humans' various levels of awareness, pointing to the aspects of our knowing and learning that may be pre-conscious or even "set-before" (built into our brains). Tall also discusses how prior learning, emotional responses, modality, and meaning all influence the ways students learn and know mathematics. I felt that Tall did not attend appropriately to how students can consciously reflect on and organize the various meanings they hold across embodied, symbolic, and axiomatic worlds. Reasoning flexibly and coherently toward developing crystalline concepts as Tall intends would seem to require the knower to consciously organize their own knowledge. Accounts of mathematical learning, in my view, must account for this.

Since we cannot fully control such conscious reflections, mathematics educators often begin by focusing on matters we can control such as the modality of our instruction or the coherence of the meanings we promote. We can try to create less discontinuity between embodied, symbolic, and formal meanings. But ultimately - as Tall's language suggests - formal, proof-oriented mathematics entails a new culture and a new set of values. We might even call it a new world. In addition to easing transitions, I would hope to help students see the epistemological value gained by leaping across this discontinuity. I claim this may involve students becoming more consciously aware of 1) the nature of their mathematical knowledge, 2) the sources of their mathematical knowledge, and 3) the methodological standards related to the a priori certainty of mathematical knowledge. Recognizing the beauty, value, and certainty of proven knowledge is ultimately at the heart of Tall's exploration in the book.

\section{Conclusion}

In closing, I think it is important to acknowledge how I may have shifted Tall's central question toward my own interests. While I felt his book did not fully answer my "how" questions about the barriers in learning to think mathematically, I sense that Tall instead was pondering, "How is it even possible for people to think mathematically, given our finite and temporal constraints?" Tall's book celebrates the amazing achievements of human minds throughout history, marvelling at the amazing feats of abstraction 
achieved by "biological brains." As someone dedicated to inviting novices into that tradition of mathematical knowing, I heartily join Professor Tall in celebrating the beauty of the process, from its most embryonic to its most advanced stages.

\section{References}

Byers, W. (2014). How humans learn to think mathematically: Exploring the three worlds of mathematics, by David Tall. Educational Studies in Mathematics, 87(3), 1-4.

Goodman, N. (1978). Ways of worldmaking. Indianapolis: Hackett Publishing.

Holland, D., Lachicotte, W. J., Skinner, D., \& Cain, C. (1998). Identity and agency in cultural worlds. Cambridge: Harvard University Press.

Kershner, R. B., \& Wilcox, L. R. (1950). The anatomy of mathematics. New York: Ronald Press.

Lakoff, G., \& Núñez, R. E. (2000). Where mathematics comes from: How the embodied mind brings mathematics into being. New York: Basic books.

Larsen, S. (2009). Reinventing the concepts of group and isomorphism: The case of Jessica and Sandra. The Journal of Mathematical Behavior, 28, 119-137.

Oehrtman, M. (2009). Collapsing dimensions, physical limitation, and other student metaphors for limit concepts. Journal for Research in Mathematics Education, 40(4), 396-426.

Simon, M., Saldanha, L., McClintock, E., Akar, G. K., Watanabe, T., \& Zembat, I. O. (2010). A developing approach to studying students' learning through their mathematical activity. Cognition and Instruction, 28(1), 70-112.

Tall, D. (Ed.). (1991). Advanced mathematical thinking. The Netherlands: Springer.

Thompson, P. W. (1994). Students, functions, and the undergraduate curriculum. In E. Dubinsky, A. H. Schoenfeld, \& J. J. Kaput (Eds.), Research in collegiate mathematics education, I: Issues in mathematics education (Vol. 4, pp. 21-44). Providence: American Mathematical Society. 